\title{
THE OPTIMAL CONSUMPTION FUNCTION IN A BROWNIAN MODEL OF ACCUMULATION PART A: THE CONSUMPTION FUNCTION AS SOLUTION OF A BOUNDARY VALUE PROBLEM ${ }^{*}$
}

\author{
Lucien Foldes \\ London School of Economics and Political Science
}

Contents:

Abstract

1. Formulation of the Brownian

Growth Model

2. Characterising of Optimal

Consumption Function

References

Discussion Paper

No. TE/96/297

March 1996
The Suntory Centre

Suntory and Toyota International Centres for Economics and Related Disciplines London School of Economics and Political Science Houghton Street London WC2A $2 \mathrm{AE}$ Tel.: 020-7955 6698

*I am indebted to Sven Rady for comments. 


\begin{abstract}
We consider a neo-classical model of optimal economic growth with c.r.r.a. utility in which the traditional deterministic trends representing population growth, technological progress, depreciation and impatience are replaced by Brownian motions with drift. When transformed to 'intensive' units, this is equivalent to a stochastic model of optimal saving with diminishing returns to capital. For the intensive model, we give sulficient conditions for optimality of a consumption plan (open-loop control) comprising a finite wellare condition, a martingale condition for shadow prices and a tratsversality condition as $t \rightarrow \infty$. We then replace these by conditions for optimality of a plan generated by a consumption function (closed-loop control), i.e. a function $\mathrm{H}(2)$ expressing log-consumption as a time-invariant, deterministic function of log-capital $z$. Making use of the exponential martingale formula we repiace the martingale condition by a non-linear, non-autonomous second order o.d.e. which an optimal consumption function must satisfy; this has the form $\Pi^{\prime \prime}(z)=\mathrm{F}\left[\mathrm{H}^{\prime}(z), Q(z), z\right]$, where $O(z)=\exp \{H(z)-z\}$. Economic considerations suggest certain limiting values which $H^{\prime}(z)$ and $O(z)$ should satisfy as $z \dashv \pm \infty$, thus defining a two-point boundary value probicm (b.v.p.) - or rather, a family of problems, depending on the values of parameters. We prove two theorems showing that a consumption function which solves the appropriate b.v.p. generates an optimal plan. Proofs that a unique solution of each b.v.p. exists will be given in a separate paper (Part B).
\end{abstract}

Key words: Consumption, capital accumulation, Brownian motion, optimisation, ordinary differential equations, boundary value problems.

AMS(MOS) subject classifications: $34 \mathrm{~B} 10,49 \mathrm{~A} 05,60 \mathrm{~J} 70,30 \mathrm{A16}, 93 \mathrm{E} 20$.

JEL subject classifications: D81, D90, E13, O41.

Abbreviated Title. Optimal Consumption as a Boundary Value Problem, Part A.

(C) Lucien Foldes. All rights reserved. Short sections of text, not to exceed two paragraphs, may be quoted without explicit permission provided that full credit, including $(0)$ notice, is given to the source. 


\section{FORMULATIOK OF THE BROWNIAN GROWTH MODEL}

As stated in the Abstract, our concern here is with the form of the optimal consumption function in a version of the traditional neo-classical model of economic growth in which the various exogenous time trends are replaced by Brownian motions with drift. We begin with an outline of such a model, based on a slightly altered version of the deterministic model considered in the standard work by Arrow and Kurz [1970], (henceforth A\&K).

Stated informally, the stochastic problem of optimal growth is to choose a random process $\bar{C}(t) \geq 0$ from a suitable class (see below) so as to maximise a welfare functional

$$
\mathrm{E} \int_{0}^{\infty} \tilde{\mathrm{U}}[\tilde{\mathrm{C}}(\mathrm{t})] \Pi(\mathrm{t}) \mathrm{e}^{-\rho(\mathrm{t})} \mathrm{dt}
$$

subject to the condition that the solution $\bar{K}(t)$ of the stochastic differential equation (s.d.e.) of growth

$$
\mathrm{d} \tilde{\mathrm{K}}(\mathrm{t})=\{\Psi[\tilde{\mathrm{K}}(\mathrm{t}), \mathrm{L}(\mathrm{t})]-\tilde{\mathrm{C}}(\mathrm{t}) \Pi(\mathrm{t})\} \mathrm{dt}-\tilde{\mathrm{K}}(\mathrm{t}) \mathrm{d} \Gamma(\mathrm{t}),
$$

with initial condition $\tilde{\mathrm{K}}(0)=\mathrm{K}_{0}>0$, be almost surely (a.s.) non-negative for all $t \geq 0$. Here $\tilde{C}(t)$ represents consumption per head of the population and $\tilde{K}(t)$ the total capital stock, all expressed in 'natural' units (such as bushels or dollars). The population - or, with a constant employment ratio, the labour force - is $\Pi(t)=\Pi(0) \exp \{\pi(t)\}$, where $\pi(t)$ is a given process and $\Pi(0)=1, \pi(0)=0$ for convenience. The 'effective' labour force is by definition $\mathrm{L}(\mathrm{t})=\exp \{\pi(\mathrm{t})+\beta(\mathrm{t})\}$, where $\beta(t)$ with $\beta(0)=0$ is another process representing labour-augmenting technological progress (or decline!). The term $\mathrm{d} \Gamma(\mathrm{t})$ represents the random rate of depreciation (or appreciation) of capital, which is omitted from the main exposition in 
A\& $K$. The production function $\Psi(K, L){ }_{1}{ }^{1}$ representing gross output in natural units, is defined for $\mathrm{K} \geq 0, \mathrm{~L} \geq 0$ with $\Psi(0, \mathrm{~L})=\Psi(\mathrm{K}, 0)=0$ and is homogeneous of degree one ('constant returns to scale'), concave and $\mathrm{C}^{2}$ (i.e. twice continuously differentiable, including one-sided limits on the axes); and for $\mathrm{K}>0, \mathrm{~L}>0$ it is increasing and strictly concave in each variable separately ('law of diminishing returns'). We write

$$
\psi(\mathrm{k})=\Psi(\mathrm{k}, 1), \text { with } \psi^{\prime}(\mathrm{k})>0>\psi^{\prime}(\mathbf{k})
$$

and further assume

(a) $0<\psi^{\prime}(0)<\infty$,

(b) $\psi^{\prime}(\infty)=0$,

$\left(\psi^{\prime}(0)\right.$ and $\psi^{\prime}(\infty)$ being defined as one-sided limits while $\psi(0)=0$.). Condition (a) departs from the usual assumption, made in $A \& K$, that $\psi^{\prime}(0)=\infty$, and although immaterial at this stage will be important for our characterisation of the optimal consumption function. As regards the functional (1), U represents 'felicity' (or 'undiscounted utility'), and $\rho(\mathrm{t})$ with $\rho(0)=0$ is a process representing 'impatience' (or random subjective discounting). The function $\tilde{U}$, defined for consumption $c \geq 0$, is assumed to have a derivative of the form $\tilde{\mathrm{U}}^{\prime}=\mathrm{c}^{-\mathrm{b}}$ with $\mathrm{b}>0$. More precisely, we assume one of the forms

$$
\tilde{U}(c)=(1-b)^{-1} c^{1-b}, \quad b \neq 1,
$$

- distinguishing between $b<1$ (positive felicity, unbounded above) and $b>1$ (negative felicity, unbounded below) - or

$$
\tilde{\mathrm{U}}(\mathrm{c})=\ln \mathrm{c} ;
$$

sometimes we consider explicitly only (5), and then it is implicit that the formulae stated remain valid for (6) with $b=1$.

Before proceeding we need to make the stochastic structure more precise. As

\footnotetext{
1 Note the use of small capitals. These will often (but not exclusively) be used to distinguish capital, labour, consumption etc considered as real variables from corresponding processes or functions of time.
} 
usual, there is given a complete probability space $(\Omega, \mathscr{t}, \mathrm{P})$ with a filtration $\left(\mathscr{t}_{\mathrm{t}} ; \mathrm{t} \geq 0\right)$ satisfying the usual conditions of right continuity and completeness; also $\mathscr{b}_{0}$ is almost trivial and $\mathscr{b}=\mathscr{b}_{\mathrm{w}}$. All processes considered will be adapted to the given filtration, which may be thought of as representing the information available to an economic planner or forecaster. There are given four processes $\beta, \gamma, \pi, \rho$ which are Brownian motions (Wiener processes) with drift relative to $\left(\mathscr{C}_{\mathrm{t}}\right)$. Explicitly, letting $\eta=(\eta(t) ; t \geq 0)$ denote any one of these processes, we have

$$
\eta(\omega, \mathrm{t})=\mu_{\eta} \mathrm{t}+\sigma_{\eta} \mathrm{B}_{\eta}(\omega, \mathrm{t})
$$

where $\mu_{\eta}$ and $\sigma_{\eta}>0$ are constants and $\mathrm{B}_{\eta}$ is standard Wiener relative to $\left(\mathscr{c}_{\mathrm{t}}\right)^{2}$ The economic interpretation of $\beta, \pi$, and $\rho$ has been indicated above. The process $\gamma$ serves to define the process $\Gamma(\mathrm{t})$ appearing in (2) as the 'martingale logarithm' of $\exp (-\gamma)$, i.e.

$$
\Gamma(\mathrm{t})=\int_{0}^{\mathrm{T}} \mathrm{e}^{\gamma(\mathrm{t})} \mathrm{d}\left(\mathrm{e}^{-\gamma(\mathrm{t})}\right), \quad \text { or }-\mathrm{d} \Gamma(\mathrm{t})=\left(\mu_{\gamma}-\frac{\mathrm{t}}{2} \sigma_{\gamma}^{2}\right) \mathrm{dt}+\sigma_{\gamma} \mathrm{dB} \gamma(\mathrm{t}), \Gamma(0)=0 .
$$

For simplicity we assume that the processes $\beta, \gamma, \pi, \rho$ are pairwise independent

For later use we set out some further definitions and formulae. We write

$$
\begin{aligned}
& \mathrm{v}(\mathrm{t})=\mathrm{v} \doteq(1-\mathrm{b}) \beta+\pi-\rho \\
& \mathrm{w}(\mathrm{t})=\mathrm{w} \doteq(\mathrm{b}-1) \gamma+\mathrm{b} \pi-\rho \\
& \mathrm{x}(\mathrm{t})=\mathrm{x} \doteq-(\gamma+\beta+\pi)
\end{aligned}
$$

and note the relations

$$
\mathrm{v}+\mathrm{x}=-(\gamma+\mathrm{b} \beta+\rho), \quad \mathrm{v}+(1-\mathrm{b}) \mathrm{x}=\mathrm{w} .
$$

The processes (9) and (10) are again Brownian motions with drift (though not independent of one another) and we may represent them as in (7). The drifts $\mu_{\eta}$ are obtained

2 i.e. $\mathrm{B}_{\eta}$ with $\mathrm{B}_{\eta}(0)=0$ is an a.s. continuous $\left(\mathscr{b}_{\mathrm{t}}\right)$-martingale with $\mathrm{E}\left\{\left[\mathrm{B}_{\eta}(\mathrm{t})-\mathrm{B}_{\eta}(\mathrm{T})\right]^{2} / \mathscr{G}_{\mathrm{T}}\right\}=\mathrm{t}-\mathrm{T}$ for $\mathrm{t} \geq \mathrm{T}$, whence it follows that $\mathrm{B}_{\eta}$ is a process with stationary independent increments and that each variable $\mathrm{B}_{\eta}(\mathrm{t})$ is normally distributed with zero expectation and variance $t$. 
from (9) by linearity, similarly the processes $\sigma_{\eta} \mathrm{B}_{\eta}$, e.g.

$$
\begin{aligned}
& w(t)=\mu_{w} t+\sigma_{w} B_{w}(t), \text { where } \\
& \mu_{w}=(b-1) \mu_{\gamma}+b \mu_{\pi}-\mu_{\rho} \\
& \sigma_{w} B_{w}=(b-1) \sigma_{\gamma} B_{\gamma}+b \sigma_{\pi} B_{\pi}-\sigma_{\rho} B_{\rho},
\end{aligned}
$$

while the variances (diffusion coefficients) and covariances are given by the usual formulae for sums, e.g.

$$
\begin{aligned}
& \sigma_{\mathrm{v}}^{2}=(1-\mathrm{b})^{2} \sigma_{\beta}^{2}+\sigma_{\pi}^{2}+\sigma_{\rho}^{2}, \\
& \sigma_{\mathrm{w}}^{2}=(\mathrm{b}-1)^{2} \sigma_{\gamma}^{2}+\mathrm{b}^{2} \sigma_{\pi}^{2}+\sigma_{\rho}^{2}, \\
& \sigma_{\mathrm{x}}^{2}=\sigma_{\gamma}^{2}+\sigma_{\beta}^{2}+\sigma_{\pi}^{2}, \\
& \sigma_{\mathrm{vx}}=\operatorname{Cov}[\mathrm{v}(1), \mathrm{x}(1)]=(\mathrm{b}-1) \sigma_{\beta}-\sigma_{\pi}^{2}, \\
& \sigma_{\mathrm{wx}}=\operatorname{Cov}[\mathrm{w}(1), \mathrm{x}(1)]=(1-\mathrm{b}) \sigma_{\gamma}^{2}-\mathrm{b} \sigma_{\pi}^{2} .
\end{aligned}
$$

Usually we write just $\mu_{\mathrm{x}}=\mu, \sigma_{\mathrm{X}}^{2}=\sigma^{2}$. Using the above calculations we further define parameters $q, n$, and $m$ as follows:

$$
\begin{aligned}
& \mathrm{e}^{-\mathrm{q}}=\mathrm{Ee}^{\mathrm{v}(1)}=\exp \left\{\mu_{\mathrm{v}}+\frac{1}{2} \sigma_{\mathrm{v}}^{2}\right\} \\
& \mathrm{e}^{-\mathrm{bn}}=\mathrm{Ee}^{\mathrm{w}(1)}=\exp \left\{\mu_{\mathrm{w}}+\frac{1}{2} \sigma_{\mathrm{w}}^{2}\right\} \\
& \mathrm{e}^{\mathrm{m}}=\mathrm{Ee}^{\mathrm{v}(1)+\mathrm{x}(1)}=\exp \left\{\mu_{\mathrm{v}+\mathrm{x}}+\frac{1}{2} \sigma_{\mathrm{v}+\mathrm{x}}^{2}\right\}
\end{aligned}
$$

Consequently we have

$$
\int_{0}^{\infty} \mathrm{Ee}^{\mathrm{v}(\mathrm{t})}<\infty \text { iff } \mathrm{q}>0 ; \quad \int_{0}^{\infty} \mathrm{Ee}^{\mathrm{w}(\mathrm{t})}<\infty \text { iff } \mathrm{n}>0
$$

Direct calculation yields the useful relations

$$
\begin{aligned}
& \mathrm{q}=\mathrm{n}+(\mathrm{b}-1)\left(\mathrm{m}+\frac{1}{2} \mathrm{~b} \sigma^{2}\right) / \mathrm{b}=\mathrm{m}+\mu+\frac{1}{2}\left[\sigma_{\gamma}^{2}+(2 \mathrm{~b}-1) \sigma_{\beta}-\sigma_{\pi}^{2}\right] \\
& \mathrm{Q} \doteq \mathrm{n}-\mathrm{m} / \mathrm{b}+\frac{1}{2} \mathrm{~b} \sigma^{2}=\mathrm{q}-\mathrm{m}+\frac{1}{2} \sigma^{2}=\mu+\sigma_{\gamma}^{2}+\mathrm{b} \sigma \xi \beta .
\end{aligned}
$$

Returning now to our informal development of the neo-classical model, we introduce 'intensive' capital and consumption processes $\overline{\mathbf{k}}$ and $\overline{\mathrm{c}}$ as well as the 'standardised' processes $\underline{\mathbf{k}}$ and $\underline{c}$ by

$$
\begin{aligned}
& \overline{\mathrm{k}}(\mathrm{t})=\overline{\mathrm{K}}(\mathrm{t}) \mathrm{e}^{-\pi(\mathrm{t})-\beta(\mathrm{t})}=\underline{\mathrm{k}(\mathrm{t}) \mathrm{e}^{\mathrm{x}(\mathrm{t})},} \\
& \overline{\mathrm{c}}(\mathrm{t})=\overline{\mathrm{C}}(\mathrm{t}) \mathrm{e}^{-\beta(\mathrm{t})}=\underline{\mathrm{c}}(\mathrm{t}) \mathrm{e}^{\mathrm{x}(\mathrm{t}),}
\end{aligned}
$$

noting that $\underline{\mathbf{k}}=\tilde{\mathrm{K}} \mathrm{e}^{\gamma}, \underline{\mathrm{c}}=\tilde{\mathrm{C}} \mathrm{e}^{\gamma+\pi}$. By virtue of the linear homogeneity of $\Psi$ we have, 
using (3),

$$
\Psi[\tilde{\mathrm{K}}(\mathrm{t}), \mathrm{L}(\mathrm{t})]=\Psi\left[\tilde{\mathrm{K}}(\mathrm{t}), \mathrm{e}^{\pi(\mathrm{t})+\beta(\mathrm{t})}\right]=\mathrm{e}^{\pi(\mathrm{t})+\beta(\mathrm{t})} \psi[\overline{\mathrm{k}}(\mathrm{t})]
$$

so that the average and marginal products of capital, in either intensive or natural units, are respectively

$$
\begin{aligned}
& \mathrm{a}[\overline{\mathrm{k}}(\mathrm{t})]=\psi[\overline{\mathrm{k}}(\mathrm{t})] / \tilde{\mathrm{k}}(\mathrm{t})=\Psi[\tilde{\mathrm{K}}(\mathrm{t}), \mathrm{L}(\mathrm{t})] / \tilde{\mathrm{K}}(\mathrm{t}), \\
& \psi^{\prime}[\overline{\mathrm{k}}(\mathrm{t})]=\mathrm{d} \psi[\overline{\mathrm{k}}(\mathrm{t})] / \mathrm{d} \overline{\mathrm{k}}(\mathrm{t})=\partial \Psi[\overline{\mathrm{K}}(\mathrm{t}), \mathrm{L}(\mathrm{t})] / \partial \tilde{\mathrm{K}}(\mathrm{t})
\end{aligned}
$$

or simply, treating capital as a real variable $\mathbf{k}$,

$$
a(k)=\psi(x) / k, \quad \psi^{\prime}(k)=\partial \Psi[k, l] / \partial k, \quad k>0 .
$$

Of course, we have $0<\psi^{\prime}(\mathrm{k})<\mathrm{a}(\mathrm{k})$ for $\mathrm{k}>0$, and we obtain $\mathrm{a}(0)=\psi^{\prime}(0)=\psi_{0}^{\prime}$ as the limit of $a(x)$ as $\mathbf{x} \downarrow 0$ and $a(\infty)=0$ as the limit as $\mathrm{k} \uparrow \infty$. We often write $(1.21)$

$$
\mathrm{z}(\mathrm{t})=\ln \overline{\mathrm{k}}(\mathrm{t}), \quad \mathrm{z}=\ln \mathrm{K},
$$

and refer to $\mathrm{z}(\mathrm{t})$ or $\mathrm{z}$ simply as $\log$-capital. The average and marginal product functions are then written as

$$
\begin{aligned}
& \mathrm{A}(\mathrm{z})=\mathrm{a}(\mathrm{k}), \quad \mathrm{M}(\mathrm{z})=\psi^{\prime}(\mathrm{k}) \\
& \mathrm{A}(-\infty)=\mathrm{M}(-\infty)=\psi_{\mathrm{O}^{\prime}}^{\prime}, \mathrm{A}(\infty)=\mathrm{M}(\infty)=0 .
\end{aligned}
$$

Note that

$$
\mathrm{A}^{\prime}(\mathrm{z})=\mathrm{da}(\mathrm{k}) / \mathrm{d} \ln \mathrm{K}=\psi^{\prime}(\mathrm{k})-\mathrm{a}(\mathrm{k})=\mathrm{M}(\mathrm{z})-\mathrm{A}(\mathrm{z})=\mathrm{A}(\mathrm{z})[\mathrm{M}(\mathrm{z}) / \mathrm{A}(\mathrm{z})-\mathrm{l}],
$$

so that $A^{\prime}(z)<0$ for $z \in l$ with $A^{\prime}( \pm \infty)=0$.

We now rewrite (2) properly in integral form, say for short

$$
\tilde{\mathrm{K}}_{\mathrm{T}}=\mathrm{K}_{\mathrm{o}}+\int_{\mathrm{O}}^{\mathrm{T}}\left(\Psi_{\mathrm{t}}-\tilde{\mathrm{C}}_{\mathrm{t}} \Pi_{\mathrm{t}}\right) \mathrm{dt}-\int_{\mathrm{O}}^{\mathrm{T}} \overline{\mathrm{K}}_{\mathrm{t}} \mathrm{d} \Gamma \mathrm{t} \text {. }
$$

This is a generalised Doléans integral equation, and for a suitable $\tilde{\mathrm{C}}$ the (semimartingale) solution is given by

$$
\tilde{\mathrm{K}}_{\mathrm{T}}=\mathrm{e}^{-\gamma(\mathrm{T})}\left\{\mathrm{K}_{\mathrm{o}}+\int_{0}^{\mathrm{T}} \mathrm{e}^{\gamma(\mathrm{t})}\left(\Psi_{\mathrm{t}}-\tilde{\mathrm{C}}_{\mathrm{t}} \Pi_{\mathrm{t}}\right) \mathrm{dt}\right\}
$$

so long as this expression remains positive, taking into account that $\gamma$ is the martingale exponential of $\Gamma$, see Jacod [1979] Ch.VI. On replacing $\Psi_{t}$ by the righthand side of (18), passing to intensive units as in (17), using the definition of $x$ in (9) and rearranging, (25) becomes 


$$
\overline{\mathrm{k}}_{\mathrm{T}} \mathrm{e}^{-\mathrm{x}(\mathrm{T})}=\mathrm{K}_{\mathrm{o}}+\int_{\mathrm{O}}^{\mathrm{T}} \mathrm{e}^{-\mathrm{x}(\mathrm{t})}\left[\psi\left(\overline{\mathrm{k}}_{\mathrm{t}}\right)-\overline{\mathrm{c}}_{\mathrm{t}}\right] \mathrm{dt} .
$$

This equation may again be rewritten in various useful ways. On the one hand, it is seen that the process $\overline{\mathbf{k}} \mathrm{e}^{-\mathrm{x}}=\underline{\mathrm{k}}$ has absolutely continuous sample paths, so that on passing to standardised units as in (17) and differentiating one can identify solutions of (26) pathwise with solutions of the ordinary d.e.

$$
\mathrm{d} \underline{\mathrm{k}}(\mathrm{t}) / \mathrm{dt}=\mathrm{e}^{-\mathrm{x}(\mathrm{T})} \psi\left[\underline{\mathrm{k}}(\mathrm{t}) \mathrm{e}^{\mathrm{x}(\mathrm{t})}\right]-\mathrm{c}(\mathrm{t}), \quad \underline{\mathrm{k}}(0)=\mathrm{K}_{0} .
$$

On the other hand, if we multiply both sides of (26) by $\mathrm{e}^{\mathrm{x}(\mathrm{T})}$, then take stochastic derivatives on both sides, use (26) to eliminate the integral and simplify, we get

$$
\mathrm{d} \overline{\mathrm{k}}_{\mathrm{t}}=\left[\psi\left(\overline{\mathrm{k}}_{\mathrm{t}}\right)-\overline{\mathrm{c}}_{\mathrm{t}}+\overline{\mathrm{k}}_{\mathrm{t}}\left(\bar{\mu}+\frac{t}{\mathrm{\sigma}} \sigma^{2}\right)\right] \mathrm{d} \mathrm{t}+\overline{\mathrm{k}}_{\mathrm{t}} \sigma \mathrm{dB}_{\mathrm{t}}, \quad \overline{\mathrm{k}}_{\mathrm{o}}=\mathrm{K}_{\mathrm{O}},
$$

or, in logarithmic form,

$$
\mathrm{d} \mathrm{z}_{\mathrm{t}}=\mathrm{d} l n \overline{\mathrm{k}}_{\mathrm{t}}=\left[\mathrm{a}\left(\overline{\mathrm{k}}_{\mathrm{t}}\right)-\overline{\mathrm{c}}_{\mathrm{t}} / \overline{\mathrm{k}}_{\mathrm{t}}+\mu\right] \mathrm{d} \mathrm{t}+\sigma \mathrm{dB}_{\mathrm{t}}, \quad \mathrm{z}_{\mathrm{o}}=\ln \mathrm{K}_{\mathrm{o}} .
$$

So far, we have not specified precisely the class of admissible consumption processes $\tilde{\mathrm{C}}$ (or $\bar{c}$ or $\underline{c}$ ). Actually, it makes little difference for the purposes of this paper whether we require consumption to be progressively measurable, or optional, or predictable, or even continuous. To be specific, we define an (admissible) consumption plan in standardised form as a non-negative, progressive process $\underline{c}=\underline{c}(\omega, t)$ such that the solution $\underline{\mathrm{k}}$ of the o.d.e. (1.27) is a.s. uniquely defined and non-negative for all $0 \leq t<\infty$, and denote by $\underline{\mathscr{B}}$ the set of all such processes. (This definition implies that $\int_{0}^{\mathrm{T}} \mathrm{c}(\omega, \mathrm{t}) \mathrm{dt}<\infty$ for all $\mathrm{T}$ a.s.). The set $\overline{\mathscr{C}}$ of consumption plans in intensive form is then the image of $\underline{\mathscr{C}}$ under $\underline{\mathrm{c}} \rightarrow \overline{\mathrm{c}}=c \mathrm{e}^{\mathrm{x}}$, or equivalently the set of nonnegative, progressive processes $\overline{\mathbf{c}}$ such that an (a.s. continuous) solution $\vec{k}$ of the s.d.e. (1.28) is uniquely defined and a.s. non-negative for $0 \leq t<\infty$. Similarly for $\overline{\mathrm{C}}$. If now we rewrite the welfare functional in standardised and intensive units we have, for $b \neq 1$,

$$
\varphi=(1-b)^{-1} \mathrm{E} \int_{0}^{\infty} \mathrm{c}(\mathrm{t})^{1-\mathrm{b}} \mathrm{e}^{\mathrm{w}(\mathrm{t})} \mathrm{dt}=(1-\mathrm{b})^{-1} \mathrm{E} \int_{\mathrm{o}}^{\mathrm{d}} \bar{c}(\mathrm{t})^{1-\mathrm{b}} \mathrm{e}^{\mathrm{v}(\mathrm{t})} \mathrm{dt},
$$

and when necessary we write $\varphi(\mathcal{c})$ or $\bar{\varphi}(\bar{c})$ to distinguish the two forms. In case $\mathrm{b}=1$, we have $\mathrm{v}=\mathrm{w}=\pi-\rho$, and the functional becomes 


$$
\varphi=\mathrm{E} \int_{0}^{\infty}[\ln \underline{\mathrm{c}}(\mathrm{t})-\gamma(\mathrm{t})-\pi(\mathrm{t})] \mathrm{e}^{\pi(\mathrm{t})-\rho(\mathrm{t})} \mathrm{dt}=\mathrm{E} \int_{0}^{\infty}[\ln \overline{\mathrm{c}}(\mathrm{t})+\beta(\mathrm{t})] \mathrm{e}^{\pi(\mathrm{t})-\rho(\mathrm{t})} \mathrm{dt} .
$$

The expected integrals in (30) and (31) are defined as Lebesgue integrals. (To avoid tedious reservations in the case $b=1$ we set $\varphi=-\infty$ if the integrals have the form $+\infty+(-\infty)$, although in fact this cannot occur under the assumptions of Theorems 2-3 below.) In (31) it is natural to drop in each expression the terms not involving consumption, and to maximise simply

$$
\varphi(\underline{c})=E \int_{0}^{\infty}[\ln \underline{c}(t)] e^{\pi(t)-\rho(t)} d t \text { or } \bar{\varphi}(\bar{c})=E \int_{0}^{\infty}[\ln \bar{c}(t)] e^{\pi(t)-\rho(t)} d t
$$

The resulting functionals are equivalent to one another, and to (1), only if the terms which are dropped are integrable; (it can be checked that this is always the case under the assumptions of Theorems 2-3).

The stochastic problem of optimal growth (or decline) can now be briefly defined. We consider $\bar{\varphi}$ (or $\varphi$ ) as an integral functional on $\overline{\mathscr{B}}$ (or $\mathscr{\mathscr { C }}$ ) and assume directly, or infer from stated assumptions, that it possesses a finite supremum $\varphi^{*}$, (i.e. that $\bar{\varphi}(\overline{\mathrm{c}}) \leq \varphi^{*}<\infty$ for all $\overline{\mathrm{c}} \in \overline{\mathscr{B}}$ and $\bar{\varphi}(\overline{\mathrm{c}})>-\infty$ for some $\overline{\mathrm{c}} \in \overline{\mathscr{B}}$ ). Then the problem expressed in intensive (or standardised) units is to find a $\bar{c}$ (or $\underline{c}$ ) which attains this supremum, if such an element exists. From now on we shall work with this formulation, leaving aside the original problem in natural units. Clearly, the transformed models can also be interpreted as models of optimal saving with diminishing returns to capital driven by two correlated Brownian motions, namely $\mathrm{v}$ and $\mathrm{x}$ in the intensive form, $w$ and $x$ in the standardised form.

Special interest attaches to plans which are defined in intensive form by specifying consumption as a function of capital only, with consumption positive whenever capital is positive. We shall write this in logarithmic form as

$$
\ln \overline{\mathrm{c}}(\mathrm{t})=\mathrm{H}[\mathrm{z}(\mathrm{t})], \quad \text { or simply } \quad \ln \overline{\mathrm{C}}=\mathrm{H}(\mathrm{z}),
$$

or equivalently

$$
\overline{\mathrm{c}} / \overline{\mathrm{x}}=\mathrm{e}^{\mathrm{H}(\mathrm{z})-\mathrm{z}}=O(\mathrm{z})
$$

and refer to $\mathrm{H}$ as the (logarithmic) consumption function and to $\theta$ as the 
consumption ratio function (or average propensity to consume out of capital). It is well known that, under some restrictions on the parameters of the model (narrower than those in Theorems 2-3 below) the values of $\bar{k}(t)$ and $\bar{c}(t)$ determined by a consumption function tend to steady state values as $t \rightarrow \infty$ in the deterministic case, while in the stochastic case the distributions of $\bar{k}(t)$ and $\bar{c}(t)$ converge to limiting distributions. Such asymptotic results are regarded as the jewels in the neo-classical crown, but we shall have nothing to say about them here. We concentrate instead on the properties of optimal consumption functions.

It is intuitively fairly clear (because of the strong Markov property of Brownian motion and the 'discounted c.r.r.a' form of utility) that an optimum in the set of consumption functions defines an optimal plan, and conversely that an optimal plan can be defined by a consumption function. We shall not prove this here, but rather adopt a constructive approach, showing that for specified ranges of parameter values there exist consumption functions which generate plans satisfying sufficient conditions for optimality. Formally, we shall define an optimal consumption function as a consumption function which generates an optimal plan. Rather surprisingly, little seems to be known about the properties of optimal consumption functions, even in the deterministic neo-classical growth model. Mirrlees [1967] gives some discussion and numerical results.

Continuous-time one sector neo-classical growth models driven by Brownian motion have received some attention in the economic literature, see Malliaris and Brock [1982] Ch.3 for a survey. The model closest to the one formulated here appears to be that considered by Merton [1975], which differs in that population is the only exogenous process, and that in the functional the generations are not weighted according to their size and there is no discounting. Actually, Merton's model is more or less equivalent to the special case of our intensive model with $\beta=\pi=\rho=0$ and $\mathbf{x}=-\gamma$, i.e. his population process behaves like our $\gamma$ rather than our $\pi$. Merton 
considers (i) the steady-state distribution of $\bar{c}$ and $\bar{k}$ induced by a given (not necessarily optimal) consumption function or fixed ratio, a problem also considered by Bourguignon [1974]; (ii) the Bellman equation for the optimal finite-horizon policy and its limit (taken informally) as $\mathrm{T} \rightarrow \infty$; (iii) the 'stochastic Ramsey problem', which consists of choosing among all consumption functions which eventually generate steady states that one which maximises expected steady-state utility. Both (ii) and (iii) lead to a certain first order o.d.e. to be solved for the 'Ramsey optimal' consumption function. Despite a rather ambiguous statement which might suggest the contrary, this is by no means the same thing as a consumption function which generates an optimal plan over an infinite horizon for a functional having a finite supremum; the latter, as we shall see, must satify a certain second order o.d.e.

The following theorem, which gives sufficient conditions for optimality in our Brownian neo-classical growth model, will serve as a verification theorem for proposed solutions. It is simply an extension of Theorem 1 of Foldes [1978] designed to take account of the presence of a concave production function. The economic intuition suggesting the conditions is also analogous, namely (i) that welfare should be finite, (ii) that along an optimal plan the shadow price process, defined as marginal utility of consumption multiplied by compound interest calculated according to the marginal productivity of capital, should be a martingale, and (iii) that the expected shadow value of the capital stock (i.e. price $\times$ quantity, in compatible units) should tend to zero as $\mathbf{T} \rightarrow \infty$. We refer to these conditions respectively as the finite welfare, martingale and transversality conditions. ${ }^{3}$ We shall not go into the necessity of these conditions here.

3 The method of proof of Theorem 1 does not depend significantly on the exogenous processes being Brownian, or on utility being 'discounted c.r.r.a'; and it does illustrate the advantage of working with standardised as well as intensive units, and so being able to use. ordinary calculus. 
THEOREM 1 (Sufficient conditions for optimality of plans). A plan $\left(\overline{\mathrm{c}}^{*}, \mathrm{k}^{*}\right)$ is optimal if the following conditions are satisfied:

(i) $\bar{\varphi}\left(\bar{c}^{*}\right)$ is finite,

(ii) the process $y$ defined by

$$
\mathrm{y}_{\mathrm{T}}=\left(\overline{\mathrm{c}}_{\mathrm{T}}^{*}\right)^{-\mathrm{b}} \exp \left\{\mathrm{v}_{\mathrm{T}}+\mathrm{x}_{\mathrm{T}}+\int_{\mathrm{O}}^{\mathrm{T}} \psi^{\prime}\left(\overline{\mathrm{k}}_{\mathrm{t}}^{*}\right) \mathrm{d} \mathrm{t}\right\}
$$

is a martingale, and

(iii) $\lim _{\mathrm{T} \rightarrow \boldsymbol{\infty}} \mathrm{E}\left[\mathrm{y}_{\mathrm{T}} \cdot \overline{\mathrm{k}}_{\mathrm{T}}^{*} \exp \left\{-\mathrm{x}_{\mathrm{T}}-\int_{\mathrm{O}}^{\mathrm{T}} \psi^{\prime}\left(\overline{\mathrm{k}}_{\mathrm{t}}^{*}\right) \mathrm{dt}\right\}\right]=0$,

or equivalently

$$
\lim _{\mathrm{T} \rightarrow \infty} \mathrm{E}\left[\mathrm{k}_{\mathrm{T}}^{*} \bar{c}_{\mathrm{T}}^{*-\mathrm{b}} \mathrm{e}^{\mathrm{v}(\mathrm{T})}\right]=0 .
$$

Proof. Let $\left(\bar{c}^{*} \bar{k}^{*}\right)$ be a plan satisfying the stated conditions and $(\bar{c}, \bar{k})$ another plan. We wish to show that $\bar{\varphi}(\overline{\mathrm{c}}) \leq \bar{\varphi}\left(\overline{\mathrm{c}}^{*}\right)$, and may assume that $\bar{\varphi}(\overline{\mathrm{c}})>-\infty$. We abridge the notation by sometimes omitting the arguments $(\omega, t)$ and write $\delta \overline{\mathrm{c}}=\overline{\mathrm{c}}-\overline{\mathrm{c}}^{*}, \delta \overline{\mathrm{k}}=\overline{\mathrm{k}}-\overline{\mathrm{k}}^{*}, \delta \underline{\mathrm{c}}=\underline{\mathrm{c}}-\underline{\mathrm{c}}^{*}, \delta \underline{\mathrm{k}}=\underline{\mathrm{k}}-\underline{\mathrm{k}}^{*}, \delta \underline{\mathrm{k}}=\mathrm{d} \delta \underline{\mathrm{k}} / \mathrm{dt} \quad$ where $\underline{\mathrm{k}}=\mathrm{ke} \mathrm{e}^{-\mathrm{x}}$, $\underline{c}=\overline{\mathrm{c}} \mathrm{e}^{-\mathrm{x}}$ etc, also $\psi^{* *}=\psi^{\prime}\left(\overline{\mathbf{k}}^{*}\right)$. We further write $\mathrm{J}_{\mathrm{T}}=\underline{\mathrm{k}}_{\mathrm{T}} \cdot \exp \left\{-\int_{0}^{\mathrm{T}} \psi^{*} \mathrm{dt}\right\}$, similarly $\mathrm{J}^{*}$ and $\delta \mathrm{J}=\mathrm{J}-\mathrm{J}^{*}$, and note that $\mathrm{j}=\left(\underline{\mathrm{k}}-\underline{\mathrm{k}} \cdot \psi^{*}\right) \exp \left\{-\int \psi^{*} \mathrm{dt}\right\}$.

Using the concavity of the felicity function $\vec{u}$, where

$$
\overline{\mathrm{u}}(\overline{\mathrm{c}})=(1-\mathrm{b})^{-1} \overline{\mathrm{c}}(1-\mathrm{b}) \text { for } \mathrm{b} \neq 1, \quad \overline{\mathrm{u}}(\overline{\mathrm{c}})=\ln \overline{\mathrm{c}} \text { for } \mathrm{b}=1,
$$

as well as (34), (17), (27) and the concavity of $\psi$, we have

$$
\begin{aligned}
\delta \overline{\mathrm{u}} \cdot \mathrm{e}^{\mathrm{v}} \leq \delta \overline{\mathrm{c}} \cdot \overline{\mathrm{c}}^{*-\mathrm{b}} \cdot \mathrm{e}^{\mathrm{v}}=\delta \overline{\mathrm{c}} \cdot \exp \left\{-\mathrm{x}-\int \psi^{* *}\right\} \cdot \mathrm{y}=\delta \underline{\mathrm{c}} \cdot \exp \left\{-\int \psi^{* *}\right\} \cdot \mathrm{y} \\
=\left\{\left[\psi\left(\underline{\mathrm{k}} \mathrm{e}^{\mathrm{x}}\right)-\psi\left(\underline{\mathrm{k}}^{*} \mathrm{e}^{\mathrm{x}}\right)\right] \mathrm{e}^{-\mathrm{x}}-\delta \underline{\mathrm{k}}\right\} \cdot \exp \left\{-\int \psi^{*}\right\} \cdot \mathrm{y} \\
\leq\left\{\delta \underline{\mathrm{k}} \cdot \psi^{\prime *}-\delta \underline{\mathrm{k}}\right\} \cdot \exp \left\{-\int \psi^{*}\right\} \cdot \mathrm{y}=-\mathrm{y} \cdot \delta \mathrm{j} .
\end{aligned}
$$

Taking expected integrals $\mathrm{E} \int_{0}^{\mathrm{T}}$ on both sides of the inequality $\delta \overline{\mathrm{u}} \cdot \mathrm{e}^{\mathrm{v}} \leq-\mathrm{y} \cdot \delta \dot{\mathrm{j}}$, we have on the left

$$
\mathrm{E}\left\{\int_{0}^{\mathrm{T}} \delta \overline{\mathrm{u}} \cdot \mathrm{e}^{\mathrm{v}} \mathrm{dt}\right\} \rightarrow \bar{\varphi}(\overline{\mathrm{c}})-\bar{\varphi}\left(\overline{\mathrm{c}}^{*}\right) \text { as } \mathrm{T}+\infty
$$

and to complete the proof we need to show that $-E\left\{\int_{0}^{T} y \cdot \delta j d t\right\} \rightarrow 0$.

Now recall that, if $y$ is a positive martingale and $\mathrm{G}$ with $\mathrm{G}(0)=0$ is an absolutely continuous process with a non-negative (adapted) derivative $\dot{G}$, then 


$$
E\left\{\int_{0}^{T} y_{t} \cdot \dot{G}_{t} d t\right\}=E\left\{y_{T} \cdot G_{T}\right\} \text { for each } T<\infty,
$$

see Foldes [1978] eqs. (1.14-15) for a simple proof. The process $\delta s$ can be written as the difference between two such processes $G$, and if the expectations of the positive and negative integrals are finite for each $\mathrm{T}<\infty$ we may replace $G$ by $\delta \mathrm{J}$ in the preceding equation. In fact, we can do better: for each $\mathrm{T}<\infty$ the random variable $\int_{0}^{T}\left|\delta j_{t}\right| d t$ is a.s. bounded, with a uniform bound for all feasible $\delta \mathrm{J}$ (see the footnote ${ }^{4}$ ); consequently

$$
E\left|\int_{0}^{T} y_{t} \cdot \delta j_{t} d t\right| \leq E\left\{\int_{0}^{T} y_{t} \cdot\left|\delta j_{t}\right| d t\right\}=E\left\{y_{T} \cdot \int_{0}^{T}\left|\delta j_{t}\right| d t\right\} \leq E y_{T} \cdot \operatorname{const}(\tau)
$$

The proof is now completed by noting that

$$
-E\left\{\int_{0}^{T} y_{t} \cdot \delta j_{t} d t\right\}=-E\left\{y_{T} \cdot \delta \mathrm{l}_{T}\right\} \leq E\left\{y_{T} j_{T}^{*}\right\} \rightarrow 0 \text { by Condition (iii). } \|
$$

COROLlary. For a plan $(\bar{c}, \bar{k})$ generated by a $\log$-consumption function $H$ with ratio function 0 , a sufficient condition for the transversality condition (35) to be satisfied is that

$$
\int_{0}^{\infty} \mathrm{E}\left[\mathrm{k}_{\mathrm{T}} \overline{\mathrm{c}}_{\mathrm{T}}^{-\mathrm{b}} \mathrm{e}^{\mathrm{v}(\mathrm{T})}\right] \mathrm{dT}=\int_{0}^{\infty} \mathrm{E} \mathrm{e}^{\mathrm{z}(\mathrm{T})-\mathrm{bH}[\mathrm{z}(\mathrm{T})]+\mathrm{v}(\mathrm{T})} \mathrm{dT}<\infty,
$$

(where for brevity we drop the star superscript). We call either of the expressions in (36) the transversality integral. Note that, for $b \neq 1$, we have

$$
(1-\mathrm{b}) \bar{\varphi}(\overline{\mathrm{c}})=\int_{0}^{\infty} \mathrm{E}\left[\overline{\mathrm{c}}_{\mathrm{T}}{ }^{1-\mathrm{b}} \mathrm{e}^{\mathrm{v}(\mathrm{T})}\right] \mathrm{d} \mathrm{x}=\int_{0}^{\infty} \mathrm{E}\left[\theta_{\mathrm{T}} \overline{\mathrm{k}}_{\mathrm{T}} \overline{\mathrm{c}}_{\mathrm{T}}-\mathrm{b} \mathrm{e}^{\mathrm{v}(\mathrm{T})}\right] \mathrm{d} \mathrm{T}
$$

where $\theta_{\mathrm{T}}=O\left(z_{\mathrm{T}}\right)=\theta\left[\ln \mathrm{k}_{\mathrm{T}}\right]$. Thus, for $\mathrm{b} \neq 1$, if $O(\mathrm{z})$ is bounded on $\mathrm{R}$, convergence of (36) implies both finite welfare and transversality; on the other hand, if $O(z)$ is

4 To obtain bounds for $\int_{0}^{T}\left|j_{t}\right| d t$, bear in mind that $\underline{k} \geq 0$, $\underline{c} \geq 0$ for feasible plans and that $0 \leq \psi(\mathrm{k})<\mathrm{k} \cdot \psi_{0}^{\prime}$ and $0<\psi^{\prime *} \leq \psi_{0}^{\prime}$. Now (27) implies, on the one hand, $\underline{\mathrm{k}} \leq \underline{\mathbf{k}} \cdot \psi_{0}^{\prime}$, hence $\underline{\mathrm{k}}_{\mathrm{t}} \leq \mathrm{k}_{0} \cdot \exp \left\{\mathrm{t} \psi_{0}^{\prime}\right\}, \dot{\mathrm{J}}_{\mathrm{t}} \leq \dot{\mathrm{k}}_{\mathrm{t}} \leq \mathrm{k}_{0} \psi_{0}^{\prime} \cdot \exp \left\{\mathrm{t} \psi_{0}^{\prime}\right\}$; and, on the other hand, $\underline{\mathbf{k}}_{\mathrm{T}}=\mathrm{k}_{0}+\int_{0}^{\mathrm{T}} \mathrm{e}^{-\mathrm{x}} \psi\left(\underline{\mathrm{k}} \mathrm{e}^{\mathrm{x}}\right) \mathrm{dt}-\int_{0}^{\mathrm{T}} \underline{\mathrm{c}} \mathrm{dt} \geq 0$, hence $\int_{0}^{\mathrm{T}} \underline{\mathrm{c}} \mathrm{dt} \leq \mathrm{k}_{0}+\psi_{0}^{\prime} \cdot \int_{0}^{\mathrm{T}} \underline{\mathrm{k}}_{\mathrm{t}} \mathrm{dt}$. Also $-\underline{\mathrm{k}} \leq \underline{\mathrm{c}}$, so $-\mathbf{j}=\left(-\underline{\mathbf{k}}+\underline{\mathbf{k}} \cdot \psi^{* *}\right) \exp \left\{-\int \psi^{*}\right\} \leq \underline{\mathrm{c}}+\underline{\mathbf{k}} \cdot \psi_{0}^{\prime}$. On integrating the bounds on $\mathrm{j}$ and $-\mathrm{j}$ and using the bounds on $\int \underline{\mathbf{c}} \mathbf{d t}$ and $\underline{\mathbf{k}}$, one finds that $\int_{0}^{\mathrm{T}}\left|\mathbf{J}_{\mathbf{t}}\right| \mathrm{dt}$ is bounded by a constant depending only on $T$. Similarly for $\int_{0}^{T}\left|\delta \dot{j}_{t}\right| d t$. 
bounded away from zero on $\mathbf{k}$, then finite welfare implies transversality.

Closely related to Brownian neo-classical growth models are models, often proposed in connection with personal investment in securities, where return or output is proportional to capital employed; thus, in the present setting, the production function $\psi$ might be replaced by a linear relation, say

$$
\psi_{l}(\overline{\mathrm{k}})=l \overline{\mathrm{k}}, \quad \overline{\mathrm{k}} \geq 0,
$$

with some real $l$. In this case we shall speak of a linear (Brownian) model, and assume without special mention a welfare functional of the form (30) or (31-31a). Strictly speaking the linear models are not special types of neo-classical growth models, since for $l>0$ the condition $\psi^{\prime}(\infty)=0$ is violated and for $l \leq 0$ the condition $\psi^{\prime}(\overline{\mathbf{k}})>0$ is violated. It is, in fact, useful to keep linear Brownian models as a separate category, since their properties are different in important respects. For example, the optimal consumption ratio (if it exists) is constant, and there is typically no steady state distribution. Sometimes it is convenient to associate with each (Brownian) neo-classical economy, say $\mathscr{N}$, a pair of linear economies, a lower linear economy $\mathscr{L}^{-}$derived from $\mathscr{N}$ by replacing $\psi(\overline{\mathrm{k}})$ with the zero function, and an upper linear economy $\mathscr{L}^{+}$in which $\psi$ is replaced by $\psi_{\mathrm{o}}^{\prime} \cdot \overline{\mathbf{k}}$. Obviously $\mathscr{N}$ is more productive than $\mathscr{L}$ in the sense that any $\overline{\mathbf{c}}$ (or $\underline{\mathrm{c}}$ ) which is feasible for $\mathscr{L}$ is also feasible for $\mathscr{N}$ but not vice versa, and similarly $\mathscr{L}^{+}$is more productive than $\mathscr{N}$ Writing $\overline{8}$ as usual for the feasible set and $\varphi^{*}$ for the least upper bound of $\bar{\varphi}$ we have

$$
\overline{\mathscr{B}}\left(\mathscr{L}^{-}\right) \overline{\mathscr{B}}(\mathscr{N}) \overline{\mathscr{B}}\left(\mathscr{L}^{*}\right) ; \quad \varphi^{*}\left(\mathscr{L}^{-}\right) \leq \varphi^{*}(\mathscr{N}) \leq \varphi^{*}\left(\mathscr{L}^{*}\right)
$$

The linear version of the present Brownian growth model with $l=0$, written in standardised units, is essentially the same as the model of saving considered in Foldes [1978] - more precisely the special case, considered in Section 1 of that paper, where the returns process is Brownian and the welfare functional is 'discounted c.r.r.a'. In this case the 'equation of growth' (27) reduces to $\mathrm{dk} / \mathrm{dt}=-\mathfrak{c}$, hence 
$\underline{k}(T)=K_{0}-\int_{0}^{T} c(t) d t$, and the constraint $\underline{k}(T) \geq 0$ for all $T$ a.s. reduces to $\int_{0}^{m} c(t) d t \leq K_{0}$ a.s. It is found that $\varphi^{*}\left(\mathscr{L}^{-}\right)$is finite if $n>0$, and then the optimal plan is defined by $\theta \equiv n_{i}$ if $b \neq 1$, we have $\varphi^{*}=K_{0}^{1-b} n^{-b} /(1-b)$. These results can be checked by applying Theorem 1 above, which remains valid in the linear case. (Actually $\mathrm{n}>0$ is also necessary for $\varphi^{*}\left(\mathscr{L}^{-}\right)$to be finite, although this is not proved in Foldes [1978]; for $b<1$ this is fairly obvious.) Of course, a linear model with $l \neq 0$ can be transformed into one with $l=0$. It suffices to replace $\mu_{\gamma}$ by $\mu_{\gamma}+l$, hence $\mu_{\mathrm{x}}$ by $\mu_{\mathrm{x}}-l$, $\mathrm{x}(\mathrm{t})$ by $\mathrm{x}(\mathrm{t})-l \mathrm{t}, \mathrm{w}(\mathrm{t})$ by $\mathrm{w}(\mathrm{t})+(\mathrm{b}-1) l \mathrm{t}$, while $\mathrm{v}$ remains unchanged; then $\underline{k}(t)$ is replaced by $\underline{k}(t) e^{-l t}, \underline{c}(t)$ by $\underline{c}(t) e^{-l t}$, while the definitions of $\bar{k}$ and $\bar{c}$ remain the same. Now $n$ is replaced in the preceding results by $\mathrm{n}+l(\mathrm{~b}-1) / \mathrm{b}$. In particular, we shall need this formula in case $l=\psi_{0}^{\prime}$. Using notation like that in (39), and denoting the optimal consumption ratio by $0^{*}$, we record that

$$
\theta^{*}\left(\mathscr{L}^{*}\right)=\mathrm{n} \text { if } \mathrm{n}>0 ; \quad \theta^{*}\left(\mathscr{L}^{*}\right)=\mathrm{N} \doteq \mathrm{n}+\psi_{0}^{\prime}(\mathrm{b}-1) / \mathrm{b} \quad \text { if } \mathrm{N}>0 .
$$




\section{CHARACTERISIRG THE OPTIMAL CONSUMPTION FUNCTION}

We turn now to the problem of constructing optimal plans for the Brownian neoclassical growth model. The procedure will be to guess properties which an optimum may be expected to possess as well as restrictions on the parameters of the model which may be expected to ensure that an optimum exists; then to show that, under the restrictions, a plan with the assumed properties satisfies the sufficient conditions for optimality stated in Theorem 1; and finally to prove that such a plan does exist. The last point is deferred to a separate paper, Foldes [1996], henceforth 'Part B'. (Of course, the conjectures are so chosen that, with minor qualifications, they will turn out also to be necessary, either for the existence of an optimum or for a given plan to be optimal; but these questions also are beyond the scope of the present paper.) Since from now on we are mainly concerned with the construction or properties of an optimal plan $\left(\overline{\mathrm{c}}^{*}, \overline{\mathrm{k}}^{*}\right)$ or $\left(\underline{\mathrm{c}}^{*}, \underline{\mathrm{k}}^{*}\right)$, we shall often drop the star superscript.

A fundamental conjecture is that an optimal plan may be generated in closedloop form by a logarithmic consumption function, say $\ln \overline{\mathrm{c}}=\mathrm{H}(\mathrm{z})$ or ln $\theta(z)=\mathrm{H}(\mathrm{z})-\mathrm{z}$ for $\mathrm{z} \in \mathrm{R}$ as in (1.32-33), and that $\mathrm{H}$ may be chosen of class $\mathrm{C}^{2}$. We then often write

$$
\theta^{\prime}(z)=[h(z)-1] \theta(z), \quad h(z)=H^{\prime}(z), h^{\prime}(z)=H^{\prime \prime}(z) .
$$

Obvious economic considerations suggest that $H$ will be increasing with limits $H(-\infty)=-\infty, H(\infty)=\infty$. On the other hand, it is conjectured that $O(z)$ and $h(z)$ tend to finite limits at both ends and so are bounded on $\mathbf{p}$.

Note that (1.29) and (1.27) can now be written more conveniently as

$$
\begin{aligned}
& \mathrm{d} z_{\mathrm{t}}=\left[\mathrm{A}\left(\mathrm{z}_{\mathrm{t}}\right)+\mu-O\left(\mathrm{z}_{\mathrm{t}}\right)\right] \mathrm{dt}+\sigma \mathrm{dB}_{\mathrm{t}}, \quad \text { or } \\
& (\mathrm{d} / \mathrm{dt})\left(\mathrm{z}_{\mathrm{t}}-\mathrm{x}_{\mathrm{t}}\right)=(\mathrm{d} / \mathrm{dt}) \ln \underline{\mathrm{k}}(\mathrm{t})=\mathrm{A}\left(\mathrm{z}_{\mathrm{t}}\right)-O\left(\mathrm{z}_{\mathrm{t}}\right), \quad \mathrm{z}_{\mathrm{o}}=\ln \mathrm{K}_{\mathrm{O}}, \mathrm{K}_{\mathrm{O}}>0 .
\end{aligned}
$$

Since $A(z)$ and $\theta(z)$ are by hypothesis both bounded, it follows readily that $\underline{k}(t)$ is (strictly) positive for all $t$, a.s., and then the same is true for $\bar{k}(t), c(t)$, and $\bar{c}(t)$. In 
particular, $H$ really does define a feasible plan.

The next conjecture is that $H$ is such that the shadow price process $y$ corresponding to the plan defined by $\mathrm{H}$ is a (true) martingale. Referring to (1.34), y may now be written as

$$
\mathrm{y}_{\mathrm{T}}=\exp \left\{-\mathrm{bH}[\mathrm{z}(\mathrm{T})]+\mathrm{v}(\mathrm{T})+\mathrm{x}(\mathrm{T})+\int_{0}^{\mathrm{T}} \mathrm{M}[\mathrm{z}(\mathrm{t})] \mathrm{d} \mathrm{t}\right\}
$$

with $\mathrm{y}(0)=\exp \left\{-\mathrm{bH}\left[\mathrm{z}_{0}\right]\right\}$, and clearly $y(\mathrm{~T})>0$ for all $\mathrm{T}$, a.s. Using Itốs Lemma and (2.2) we may write

$$
\mathrm{H}\left[\mathrm{z}_{\mathrm{T}}\right]=\mathrm{H}\left[\mathrm{z}_{\mathrm{O}}\right]+\int_{0}^{\mathrm{T}}\left\{\mathrm{H}^{\prime}\left(\mathrm{z}_{\mathrm{t}}\right)\left[\mathrm{A}\left(\mathrm{z}_{\mathrm{t}}\right)+\mu-Q\left(\mathrm{z}_{\mathrm{t}}\right)\right]+\sigma^{2} \mathrm{H}^{\prime \prime}\left(\mathrm{z}_{\mathrm{t}}\right)\right\} \mathrm{dt}+\sigma \int_{\mathrm{O}}^{\mathrm{T}} \mathrm{H}^{\prime}\left(\mathrm{z}_{\mathrm{t}}\right) \mathrm{dB} \mathrm{B}_{\mathrm{t}}
$$

- where $\mathrm{B}=\mathrm{B}_{\mathrm{X}^{\prime}}, \mu=\mu_{\mathrm{x}^{1}} \sigma=\sigma_{\mathrm{x}^{\prime}}$, cf. (1.9-1.12) - and substitute this expression for $\mathrm{H}\left[\mathrm{z}_{\mathrm{T}}\right]$ into (4). On the other hand, $\mathrm{y}$ will be a positive martingale if we can represent it in the form

$$
\mathrm{y}(\mathrm{T})=\mathrm{y}(0) \cdot \exp \left\{\Sigma_{\eta}\left[\int_{0}^{\mathrm{T}} \mathrm{h}_{\eta}(\mathrm{t}) \mathrm{dB}(\mathrm{t})-\mathrm{t} \int_{0}^{\mathrm{T}} \mathrm{h}_{\eta}^{2}(\mathrm{t}) \mathrm{dt}\right]\right\}, \quad \eta=\beta, \gamma, \pi, \rho,
$$

for all $T$, with bounded (adapted) processes $h_{\eta}$, see Liptser and Shiryaev [1977] p.232 ff. In order to determine suitable $h_{\eta}$, we equate (6) with (4) - after substituting from (5) - take logarithms on both sides of the resulting identity, write out explicitly the expressions for $\mathrm{v}, \mathrm{w}$ and $\mathrm{x}$ in terms of $\eta=\beta, \gamma, \pi, \rho$, write each $\eta_{\mathrm{t}}$ as $\mu_{\eta} \mathrm{t}+\sigma_{\eta} \mathrm{dB} \eta(\mathrm{t})$, and finally equate separately the coefficients of each of the four differentials $\mathrm{dB}_{\eta}$ on both sides as well as the coefficients of $\mathrm{dt}$. This yields (2.7) $\mathrm{h}_{\gamma}(\mathrm{t})=\left[\mathrm{bH}^{\prime}\left(\mathrm{z}_{\mathrm{t}}\right)-1\right] \sigma_{\gamma} ; \mathrm{h}_{\beta}(\mathrm{t})=\mathrm{b}\left[\mathrm{H}^{\prime}\left(z_{\mathrm{t}}\right)-1\right] \sigma_{\beta} ; \mathrm{h}_{\pi}(\mathrm{t})=\mathrm{bH}^{\prime}\left(\mathrm{z}_{\mathrm{t}}\right) \sigma_{\pi} ; \mathrm{h}_{\rho}(\mathrm{t})=-\sigma_{\rho}$. (2.8) $-\frac{1}{2} \Sigma_{\eta} h_{\eta}^{2}(\mathrm{t})=-\mathrm{bH}^{\prime}\left(\mathrm{z}_{\mathrm{t}}\right)\left[\mathrm{A}\left(\mathrm{z}_{\mathrm{t}}\right)-\theta\left(\mathrm{z}_{\mathrm{t}}\right)+\mu\right]-\frac{1}{2} \mathrm{~b} \sigma^{2} \mathrm{H}^{\prime \prime}\left(\mathrm{z}_{\mathrm{t}}\right)-\left(\mu_{\gamma}+\mathrm{b} \mu_{\beta}+\mu_{\rho}\right)+\mathrm{M}\left(\mathrm{z}_{\mathrm{t}}\right)$. The $h_{\eta}$ are bounded processes since $H^{\prime}$ is bounded by assumption. Inserting the expressions (7) into the left-hand side of (8) and rearranging, using the relations $(1.9-1.13)$, the resulting equation may be written

$$
\mathrm{b} \sigma^{2} \mathrm{H}^{\prime \prime}=\mathrm{b}^{2} \sigma^{2}\left(\mathrm{H}^{\prime}\right)^{2}+2 \mathrm{bH}\left[0-\mathrm{n}+\mathrm{m} / \mathrm{b}-\frac{1}{2} \mathrm{~b} \sigma^{2}-\mathrm{A}\right]+2[\mathrm{M}-\mathrm{m}]
$$

where $H^{\prime \prime}, H^{\prime}, O, A$ and $M$ are functions of $z_{t}=z(\omega, t)$, with $O\left(z_{t}\right)=\exp \left\{H\left(z_{t}\right)-z_{t}\right\}$. It follows that $y$ in (4) can be written in the form (6) if (9) is satisfied identically for all $t \geq 0$ a.s., and then $y$ will be a martingale. This will be the case, a fortiori, if (9), with 
$\mathrm{H}^{\prime \prime}, \mathrm{H}^{\prime}, \theta, \mathrm{A}, \mathrm{M}$ (and hence $\mathrm{H}$ ) considered as functions of the real variable $\mathrm{z}$ (rather than the process $\mathrm{z}_{\mathrm{t}}$ ), is satisfied for all $\mathrm{z} \in \mathbf{l}$. But this is to require that $\mathrm{H}(\mathrm{z})$, or equivalently $\mathrm{O}(\mathrm{z})=\exp \{\mathrm{H}(\mathrm{z})-\mathrm{z}\}$, satisfy $(9)$ considered as a second order o.d.e. For purposes of analysis it is usually convenient to replace this equation by a first order system $S=(F, G)$, say

(2.10) $\quad \mathrm{h}^{\prime}=\mathrm{F}(\mathrm{h}, 0, \mathrm{z})=\mathrm{bh}^{2}+\left(2 / \sigma^{2}\right) \mathrm{h}\left[\theta-\mathrm{n}+\mathrm{m} / \mathrm{b}-\frac{1}{2} \mathrm{~b} \sigma^{2}-\mathrm{A}(\mathrm{z})\right]+2[\mathrm{M}(\mathrm{z})-\mathrm{m}] / \mathrm{b} \sigma^{2}$

$$
\theta^{\prime}=\mathrm{G}(\mathrm{h}, 0, \mathrm{z})=(\mathrm{h}-1) \theta
$$

where $\mathrm{h}=\mathrm{H}^{\prime}, \mathrm{h}^{\prime}=\mathrm{H}^{\prime \prime}$. Here we shall consider this system only for $\theta>0$; (note that, because $\theta^{\prime}=(\mathrm{h}-1) \theta, O(\mathrm{z})$ has constant sign along any solution). Also, we shall consider only proper solutions with $\mathrm{H}$ (or equivalently $\theta$ ) of class $\mathrm{C}^{2}$ on their intervals of definition; (no distributions). If one sets $\sigma^{2}=0$ in (9), one gets a first order equation consistent with the system analysed by $A \& K$.

We shall study $S=(F, G)$ as a system in its own right in Part $B$. Here we consider informally the problem of choosing a particular solution $\left(\mathrm{h}^{*}, \mathrm{O}^{*}\right)$ which will define an optimal consumption plan, anticipating later work where necessary. Obviously a 'candidate' solution must be defined on the whole of $\ell$ and, as already specified, it should be $\mathrm{C}^{2}$, with $0^{*}$ and $\mathrm{h}^{*}$ positive for $\mathrm{z} \in \mathbb{R}$ and with finite, non-negative limits for both $0^{*}$ and $h^{*}$ at $z= \pm \infty$; this implies that the solution is bounded on $n$. (We say that a solution is bounded, without further qualification, if both $\mathrm{h}$ and $\theta$ are bounded). Further, it is clear from the preceding discussion that any $\mathrm{C}^{2}$ solution which is defined and bounded on with $\theta>0$ will define a feasible plan for which the martingale condition in Theorem 1 is satisfied. Typically there are many of these. It therefore remains to choose one of them which generates a plan satisfying the finite 
welfare and transversality conditions, if such a choice is possible. ${ }^{5}$ Unfortunately, there seems to be no way to translate natural economic and mathematical requirements for an optimal solution directly into an initial value problem. We shall instead seek 'boundary' conditions, as $z \rightarrow \infty$ and $z \rightarrow-\infty$, which represent reasonable consumption behaviour when the economy is very rich or very poor, and characterise the optimal consumption function as the solution of an appropriate two-point boundary value problem (b.v.p.). The boundary values naturally depend on the parameters of the model, sometimes with qualitative ('structural') changes accompanying transitions among different ranges of parameter values.

The rest of this Section will accordingly consider the two-fold problem of (i) identifying categories of parameter values for each of which an optimal consumption function is thought to exist and formulating an appropriate b.v.p. for each category, then (ii) proving in each case that a solution of the b.v.p. (if one exists) generates a plan satisfying the finite welfare and transversality conditions. There then remains for Part $B$ the phase analysis of $S$ and the proof that a solution of the appropriate b.v.p. exists in each case.

Two ways of forming conjectures about reasonable boundary values are open. One is to use known results about economic models related to the stochastic neoclassical model. The other is to analyse the system $\mathrm{S}$ in order to identify b.v.p.s for which a solution might exist. We adopt the former approach in the present Section and defer the latter, which requires different techniques, to Part B.

As was mentioned earlier, one can associate with our Brownian neo-classical

\footnotetext{
${ }^{5}$ A priori there could be more than one optimal plan, but in fact the usual arguments based on the convexity of the feasible set $\overline{\mathcal{C}}$ and the strict concacity of $\bar{\varphi}$ imply uniqueness up to null sets. We shall not go into this issue here. The fact that an optimal consumption function constructed by the method employed here is unique will follow from arguments to be presented in Part B.
} 
economy $\mathscr{N}$ an upper and a lower linear economy - see $(1.38-40)$. Now, if $b<1, \bar{\varphi}$ is positive, and a necessary condition for a finite supremum $\varphi^{*}$ in $\mathscr{N}$ is that $\varphi^{*}\left(\mathscr{L}^{-}\right)<\infty$, or equivalently $\mathrm{n}>0$. But then $\theta^{*}\left(\mathscr{L}^{-}\right)=\mathrm{n}$, and it is reasonable to assume that, as $\mathbf{z} \rightarrow \infty$, so that $\overline{\mathbf{k}} \rightarrow \infty$ and $\psi^{\prime}(\overline{\mathrm{k}}) \rightarrow 0$, the optimal consumption ratio $\theta^{*}(\mathrm{z})$ in $\mathscr{N}$ also tends to $n$; then the equation $\theta^{\prime}=(\mathrm{h}-1) \theta$ gives $\mathrm{h}=1$ as the limiting value for $h^{*}(\mathrm{z})$. Thus, if $\mathrm{b}<1$, we shall always assume that $\mathrm{n}>0$, and take as our (conjectural) boundary condition

$$
0^{*}(\infty)=\mathrm{n}, \quad \mathbf{h}^{*}(\infty)=1 .
$$

Next, if $\mathrm{b}>1, \bar{\varphi}$ is negative, and a necessary condition for a finite supremum $\varphi^{*}$ in $\mathscr{N}$ is that $\varphi^{*}\left(\mathscr{L}^{+}\right)>-\infty$, or equivalently $\mathrm{N}=\mathrm{n}+\psi_{0}^{\prime}(\mathrm{b}-1) / \mathrm{b}>0$. But then $\theta^{*}\left(\mathscr{L}^{+}\right)=\mathrm{N}$, and it is reasonable to assume that, as $\mathrm{z} \rightarrow-\infty$, so that $\overline{\mathrm{k}} \rightarrow 0$ and $\psi^{\prime}(\overline{\mathrm{k}}) \rightarrow \psi_{0}^{\prime}$, the optimal ratio $\theta^{*}(\mathrm{z})$ in $\mathscr{N}$ also tends to $\mathrm{N}$ and hence $\mathrm{h}^{*}(\mathrm{z}) \rightarrow 1$. Thus, if $\mathrm{b}>1$, we shall always assume that $\mathrm{N}>0$, and take as our (conjectural) boundary condition

$$
0^{*}(-\infty)=\mathrm{N}, \quad \mathrm{h}^{*}(-\infty)=1
$$

It may further happen that $\mathrm{N}>0$ when $\mathrm{b}<1$, or that $\mathrm{n}>0$ when $\mathrm{b}>1$; these conditions are sufficient for $\varphi^{*}$ to be finite. In such cases we impose both conditions (11) and (12).

If $b=1$, the finite supremum condition is different, but we have $n=N=q$, and the optimal saving ratio in both $\mathscr{L}^{-}$and $\mathscr{L}^{+}$is again equal to this number if it is positive; we therefore retain both the conditions (11) and (12).

In case both conditions (11) and (12) apply we refer to a 'Type 1' b.v.p. and state the following theorem, which will be proved later:

Theorem 2 ('Type 1' b.v.p.s). Let $\mathrm{b}>0, \mathrm{n}>0$ and $\mathrm{N}>0$.

A solution $\left(h^{*}, 0^{*}\right)$ of the system $S=(F, G)$ which is defined for all $z \in R$, and has limits as $z+\infty$ and $z \rightarrow-\infty$ given by the boundary conditions (2.11) and (2.12), generates an optimal plan. 
This problem does not exhaust the possibilities. It can happen that an optimal plan exists in $\mathscr{N}$ with $\mathrm{b}<1, \mathrm{n}>0 \geq \mathrm{N}$, or with $\mathrm{b}>1, \mathrm{~N}>0 \geq \mathrm{n}$. Known results for the case of certainty are suggestive here, although they relate to economies with $\psi_{0}^{\prime}=\infty$, so that $\mathrm{N}=-\infty$ if $\mathrm{b}<1$ and $\mathrm{N}=\infty$ if $\mathrm{b}>1$. Specifically, let $\sigma_{\eta}^{2}=0$ for $\eta=\beta, \gamma, \pi, \rho$ and suppose further that $\mu_{\gamma}=0$ and $\mu_{\eta}>0$ for $\eta \neq \gamma$. These assumptions are commonly considered in the case of certainty, and they ensure in particular that along an optimal plan the values of $\bar{k}(t)$ and $\bar{c}(t)$ tend, as $t \rightarrow \infty$, to a steady state which is independent of starting values. In this case, the parameters defined in (1.13-16) satisfy:

$$
\begin{aligned}
& \mathrm{q}=(\mathrm{b}-1) \mu_{\beta}-\mu_{\pi}+\mu_{\rho}, \mathrm{bn}=-\mathrm{b} \mu_{\pi}+\mu_{\rho}, \mathrm{m}=\mathrm{b} \mu_{\beta}+\mu_{\rho}>0, \\
& \mu=-\left(\mu_{\beta}+\mu_{\rho}\right)<0, \mathrm{q}=\mathrm{n}+(\mathrm{b}-1) \mathrm{m} / \mathrm{b}=\mathrm{m}+\mu,
\end{aligned}
$$

and it is known that an optimum exists iff $q>0$, see A\&K pp. 70-72, also Koopmans [1965]. Reverting to our stochastic growth model, we may conjecture that $q>0$ can replace $\mathrm{N}>0$ when $\mathrm{b}<1$, or $\mathbf{n}>0$ when $\mathrm{b}>1$, in a set of sufficient conditions for the existence of an optimum, (the half-variance terms in the definition of $q$ being somehow attributable to Itô's Lemma). For $b=1$ we have $q=\mathbf{n}=\mathbf{N}$, so there is nothing new. Now the boundary condition (11) still makes sense if $b<1$, as does (12) if $b>1$, but a new condition is needed for the other end. Presumably $\theta^{*}(-\infty)=0$ if $\mathrm{b}<1$ with $\mathrm{N}<0$, and $\theta^{*}(\infty)=0$ if $\mathrm{b}>1$ with $\mathrm{n}<0$, but the exact limiting values for $h^{*}(z)$ are not obvious (at least to me) on the basis of economic intuition.

However, two further conditions may be suggested. Presumably $0^{*}(\mathrm{z})$ decreases for large negative $\mathrm{z} \downarrow-\infty$ in the former case and decreases for large positive $\mathrm{z} \uparrow \infty$ in the latter, so $\theta^{\prime}=(\mathrm{h}-1) 0$ suggests a limit $\mathrm{h}^{*}(-\infty) \geq 1$ in the former case and $h^{*}(\infty) \leq 1$ in the latter. We also want the transversality integral (1.36) to converge. Bearing in mind that $\mathrm{Ee}^{\mathrm{v}(\mathrm{t})}=\mathrm{e}^{-\mathrm{qt}}$, a reasonable suggestion is that $\exp \{z-b H(z)\}$ should stay bounded as $z \rightarrow-\infty$ if $b<1$ with $N \leq 0<q$, and should 
stay bounded as $z+\infty$ if $\mathbf{b}>1$ with $\mathbf{n} \leq 0<\mathrm{q}$; a simple condition ensuring this is that $1-\mathrm{bh}^{*}(-\infty)>0$ in the former case, $1-\mathrm{bh}^{*}(\infty)<0$ in the latter. Putting these remarks together, we propose the boundary conditions

$$
\begin{array}{ll}
\theta^{*}(-\infty)=0, \quad 1 \leq h^{*}(-\infty)<1 / b & \text { if } b<1 \text { and } q>0 \geq N, \\
\theta^{*}(+\infty)=0, \quad 1 \geq h^{*}(+\infty)>1 / b & \text { if } b>1 \text { and } q>0 \geq n .
\end{array}
$$

Whenever one of these conditions applies we refer to a 'Type 0' b.v.p. We are now ready to state

Тнеовем 3 ('Type 0' b.v.p.s).

(i) Let $\mathrm{b}>1, \mathrm{~N}>0$ and $\mathrm{q}>0 \geq \mathrm{n}$.

A solution of $S=(F, G)$ which is defined for all $z \in l$, and has limits as $z \rightarrow \infty$ and $\mathrm{z} \rightarrow-\infty$ given by the boundary conditions (2.15) and (2.12), generates an optimal plan.

(ii) Let $b<1, n>0$ and $q>0 \geq N$.

A solution of $S=(F, G)$ which is defined for all $z \in R$, and has limits as $z \rightarrow \infty$ and $z \rightarrow-\infty$ given by the boundary conditions (2.11) and (2.14), generates an optimal plan.

It will be shown in Part B that solutions of the b.v.p.s defined by the statements of Theorems 2 and 3 exist.

We turn to proofs of Theorems 2 and 3 . In each of the cases considered we have to show that the finite welfare and transversality conditions of Theorem 1 are satisfied. PROOF OF THEOREM 2.

In what follows, $\bar{c}, \bar{k}, y$ will refer to the plan generated by the solution $(h, \theta)$ satisfying the stated conditions; stars are often omitted for brevity. Feasibility is obvious because $\theta(z)$ is bounded on $R$.

(i) Suppose frrst that $b<1$. Since $\theta$ is continuous and positive with positive limits at $\mathrm{z}= \pm \infty$, it is bounded away from zero. Finite welfare follows immediately from

$$
0<\bar{\varphi}(\overline{\mathrm{c}}) \leq \varphi^{*} \leq \varphi^{*}\left(\mathscr{L}^{*}\right)<\infty,
$$

and since $\theta$ is bounded away from zero we know from the Corollary to Theorem 1 
that finite welfare implies transversality.

(ii) Now let $b>1$. The method used for $b<1$ does not work because it is not known in advance that $\bar{\varphi}(\overline{\mathrm{c}}) \geq \varphi^{*}\left(\mathscr{L}^{-}\right)$. A direct proof of finite welfare is needed, and then transversality will follow as before. We have to show that

$$
\overline{\mathrm{c}}_{\mathrm{o}}^{1-\mathrm{b}}(1-\mathrm{b}) \bar{\varphi}(\overline{\mathrm{c}})=\int_{0}^{\infty} \mathrm{E} \exp \left\{(1-\mathrm{b})\left[\mathrm{H}\left(\mathrm{z}_{\mathrm{T}}\right)-\mathrm{H}\left(\mathrm{z}_{0}\right)\right]+\mathrm{v}_{\mathrm{T}}\right\} \mathrm{dT}
$$

is finite. Using the formula (4) for $y(T)$ and noting that $v+(1-b) x=w$ by $(1.10)$, this may be rewritten as

$$
\int_{0}^{\infty} E\left[\left(y_{T} / y_{0}\right)^{(b-1) / b} \exp \left[w_{T}+(1-b) \int_{0}^{T} M(t) d t / b\right]\right] d r .
$$

We now replace $\mathrm{y}_{\mathrm{T}} / \mathrm{y}_{0}$ by its formula from (6), with the $h_{\eta}$ given by (7). We also replace $w(T)$ by $\mu_{w} T+\sigma_{w} B_{w}(T)$, then $\sigma_{w} B_{w}$ by its formula in (1.11) and $\mu_{\mathrm{w}}$ by $-\mathrm{bn}-\frac{1}{5} \sigma_{\mathrm{W}}^{2}$ - see $(1.13)$ - and finally replace $\sigma_{\mathrm{W}}^{2}$ in the last-mentioned expression by its formula in (1.12). In the exponents of the resulting expression we collect the Brownian terms, which have the form

$$
\begin{aligned}
& \mathrm{R}(\mathrm{T})=\Sigma_{\eta} \int_{0}^{\mathrm{T}} \mathbf{r}_{\eta}(\mathrm{t}) \mathrm{dB}_{\eta}(\mathrm{t}), \quad \eta=\gamma, \beta, \pi, \rho, \text { where } \\
& \mathrm{r}_{\gamma}=(\mathrm{b}-1) \mathrm{H}^{\prime} \sigma_{\gamma}, \mathbf{r}_{\beta}=(\mathrm{b}-1)\left(\mathrm{H}^{\prime}-1\right) \sigma \beta^{\prime}, \mathbf{r}_{\pi}=\left[(\mathrm{b}-1)\left(\mathrm{H}^{\prime}-\mathrm{l}\right)+\mathrm{b}\right] \sigma_{\pi^{\prime}} \mathbf{r}_{\rho}=-\sigma_{\rho^{\prime}}
\end{aligned}
$$

then subtract and add back

$$
-\frac{1}{2}\langle\mathrm{R}\rangle_{\mathrm{T}}=-\frac{\mathrm{t}}{3} \Sigma_{\eta} \int_{0}^{\mathrm{T}} \mathrm{r}_{\eta}^{2}(\mathrm{t}) \mathrm{d}(\mathrm{t})
$$

noting that $\exp \left\{R_{T}-\frac{1}{2}\langle R\rangle_{T}\right\}$ is a (true) martingale since $H^{\prime}$ is bounded. After simplifying, using $\sigma_{\mathbf{X}}^{2}=\sigma_{\gamma}^{2}+\sigma_{\beta}^{2}+\sigma_{\pi}^{2}$, it is found that (17) becomes, in abridged notation,

$$
\int_{0}^{\infty} E \exp \left[R_{T}-\frac{1}{2}\langle R\rangle_{T}+(1-b) \int_{0}^{T}\left[\frac{1}{2} \sigma_{x}^{2}\left(H^{\prime}\left(z_{t}\right)-1\right)^{2}+M\left(z_{t}\right) / b\right] d t-n T\right) d T .
$$

Since $b>1$, dropping the coefficient of $(1-b)$ cannot decrease this expression, and since the expectation of the martingale for each $T$ is one, the whole expression cannot exceed $\int \mathrm{e}^{-\mathrm{nT}} \mathrm{dT}$ and so converges since $\mathrm{n}>0 . \|$ Note that in this proof we had to use the martingale property of $y$.

(iii) Let $b=1$. We have $\mathbf{v}=\mathbf{w}=\pi-\rho$ and $\mathbf{n}=\mathbf{N}=\mathrm{q}$ by assumption. Since $0=\bar{c} / \bar{k}$ is bounded away from zero, say $O(z) \geq 0 .>0$, the transversality integral 
(1.36) converges by

$$
\int_{0}^{\infty} E\left[\mathrm{k}_{t} \bar{c}_{t}^{-1} e^{v(t)}\right] d t \leq\left(1 / \theta_{-}\right) \int_{0}^{\infty} E e^{v(t)} d t=\left(1 / \theta_{-}\right) \int_{0}^{\infty} e^{-q t} d t<\infty .
$$

In the present case, finite welfare must be verified separately. Using the form of $\bar{\varphi}$ given in (1.31a), we have

$$
\bar{\varphi}(\bar{c})=\int_{0}^{\infty} E\left[\ln \bar{c}_{\mathrm{t}} \cdot \mathrm{e}^{\mathrm{v}(\mathrm{t})}\right] \mathrm{dt}=\int_{0}^{\infty} \mathrm{E}\left[\left\{\ln \theta\left(\mathrm{z}_{\mathrm{t}}\right)+\mathrm{z}_{\mathrm{t}}\right\} \mathrm{e}^{\mathrm{v}(\mathrm{t})}\right] \mathrm{dt}
$$

and since $\ln \theta$ is bounded on $\$$ the part of the integral involving $\ln \theta$ converges by an argument like that just given for transversality. Now, referring to (1.29), we have

$$
\mathrm{z}(\mathrm{T})=\mathrm{z}_{\mathrm{o}}+\int_{\mathrm{o}}^{\mathrm{T}}\left\{\mathrm{A}\left(\mathrm{z}_{\mathrm{t}}\right)-O\left(\mathrm{z}_{\mathrm{t}}\right)+\mu\right\} \mathrm{dt}+\sigma \mathrm{B}(\mathrm{T}),
$$

and since $\mathrm{A}-\theta+\mu$ is bounded as a function of $\mathrm{z} \in \mathrm{R}$ it is seen, on substituting into (18), that the part of the integral involving $\mathrm{z}_{0}$ and $\int(\mathrm{A}-\theta+\mu) \mathrm{dt}$ converges because $\mathrm{Ee}^{\mathrm{v}(\mathrm{T})}=\mathrm{e}^{-\mathrm{qT}}$ with $\mathrm{q}>0$. It remains to consider

$$
\int_{0}^{\infty} \mathrm{E}\left[\sigma \mathrm{B}(\mathrm{T}) \mathrm{e}^{\mathrm{vT}}\right] \mathrm{dr} \text {. }
$$

Now $-\sigma \mathrm{B}=\sigma_{\gamma} \mathrm{B}_{\gamma}+\sigma_{\beta} \mathrm{B}_{\beta}+\sigma_{\pi} \mathrm{B}_{\pi}$ and $\mathrm{v}=\pi-\rho$, and since $\beta, \gamma, \pi, \rho$ are independent and $\mathrm{B}_{\gamma}, \mathrm{B}_{\beta}$ have zero expectations, the terms involving these two motions vanish and we are left (apart from the sign) with

$$
\int_{0}^{\infty} \mathrm{E}\left[\sigma_{\pi} \mathrm{B} \pi(\mathrm{T}) \mathrm{e}^{\pi(\mathrm{T})-\rho(\mathrm{T})}\right] \mathrm{dT}=\int_{0}^{\mathrm{m}} \mathrm{e}^{\mu_{\pi} \mathrm{T}} \cdot \mathrm{Ee}^{-\rho(\mathrm{T})} \cdot \mathrm{E}\left[\sigma_{\pi} \mathrm{B}_{\pi}(\mathrm{T}) \mathrm{e}^{\sigma_{\pi} \mathrm{B}}(\mathrm{T})\right] \mathrm{d} \mathrm{T} .
$$

Write $\chi=\sigma_{\pi} \mathrm{B}_{\pi}(\mathrm{T})$ and $\mathrm{s}=\sigma_{\pi} \sqrt{\mathrm{T}}$ for the moment. $\chi$ is a Gaussian variable with zero expectation and standard deviation $s_{1}$ and one has

$$
\begin{aligned}
& \mathrm{E}\left[\chi \mathrm{e}^{\chi}\right]=\mathrm{E}\left[(\mathrm{d} / \mathrm{d} \alpha)\left(\mathrm{e}^{\alpha \chi}\right)\right]_{\alpha=1}=\left[(\mathrm{d} / \mathrm{d} \alpha)\left(\mathrm{Ee}^{\alpha \chi}\right)\right]_{\alpha=1} \\
& =\left[(\mathrm{d} / \mathrm{d} \alpha)\left(\mathrm{e}^{\frac{1}{2} \alpha^{2} \mathrm{~s}^{2}}\right)\right]_{\alpha=1}=\mathrm{s}^{2} \mathrm{e}^{\frac{1}{2} \mathrm{~s}^{2}}=\sigma_{\pi}^{2} \mathrm{Te}^{\frac{1}{2} \sigma_{\pi}^{2} \mathrm{~T}} .
\end{aligned}
$$

Inserting (21) in (20) and using the definition of $q$ we have simply the convergent integral $\int_{0}^{\infty} \sigma_{\pi}^{2} \mathrm{Te} \mathrm{e}^{-\mathrm{q} \mathrm{T}} \mathrm{dr} . \|$ Incidentally, the calculations showing the convergence of the terms omitted in passing from (1.31) to (1.31a) are of the same kind.

PROOF OF THEOREM 3.

We consider case (i), $b>1$. It suffices to show that the transversality integral (1.36) converges. For suitable numbers $z_{\triangleleft}<\mathbf{z}^{\nabla}$ to be determined later, define the following 
indicators of $(\omega, \mathrm{t})$ sets:

$$
I_{-}=I\left\{z(\omega, t)<z_{\triangleleft}\right\}, I_{0}=I\left\{z_{\triangleleft} \leq z(\omega, t) \leq z^{\triangleright}\right\}, I_{+}=I\left\{z(\omega, t)>z^{\triangleright}\right\} .
$$

Let $z^{\triangleright}$ be so large that $H^{\prime}(z)>1 / b$ for $z>z^{\triangleright}$; then, in abridged notation,

$$
\mathrm{E} / \mathrm{I}, \mathrm{e}^{\mathrm{z}(\mathrm{t})-\mathrm{bH}[\mathrm{z}(\mathrm{t})]+\mathrm{v}(\mathrm{t})} \mathrm{dt} \leq \mathrm{e}^{\mathrm{z}^{\Delta}-\mathrm{bH}\left(\mathrm{z}^{D}\right)} \mathrm{E} / \mathrm{e}^{\mathrm{v}(\mathrm{t})} \mathrm{dt}=\text { const } \cdot 1 / \mathrm{q} \text {. }
$$

The continuous function $z-b h(z)$ is bounded on the real interval $\left[z_{4}, z^{D}\right\}$, so that an inequality like (22) applies (with a different constant) if $I_{+}$is replaced by $I_{0}$. It is therefore enough to prove the convergence of (1.36) restricted to $I_{\text {. . Since }} O(z) \rightarrow \mathrm{N}>0$ as $z \rightarrow-\infty, O(z)$ is bounded below on the real interval $\left(-\infty, z_{\triangleleft}\right)$ by some $\theta_{-}>0$, and since $O(z)=\mathrm{e}^{\mathrm{H}(\mathrm{z})-\mathrm{z}}$ we have $\mathrm{e}^{\mathrm{z}-\mathrm{bH}(\mathrm{z})}=\theta^{-\mathrm{b}} \mathrm{e}^{(1-\mathrm{b}) \mathrm{z}}$, so that

$$
E / I_{-} e^{z(t)-b H[z(t)]+v(t)} d t \leq\left(0_{-}\right)^{-b} E / I_{-} e^{(l-b) z(t)+v(t)} d t
$$

and it is enough to show the convergence of the last expected integral for some suitable $z_{\triangleleft}$. To define such a number, let $\delta$ be such that

$$
0<\delta<\mathrm{N} \text { and }(\mathrm{b}-1) \delta<\mathrm{N}
$$

and choose $z_{\triangleleft}$ so far left that $z_{\triangleleft}<z_{0}=\ln K_{0}$ and

$$
|O(\mathrm{z})-\mathrm{N}|<\delta / 2 \text { and } \mathrm{A}(\mathrm{z})>\psi_{\mathrm{O}}^{\prime}-\delta / 2 \text { for } \mathrm{z}<\mathrm{z}_{\triangleleft}+\delta
$$

We now consider the process $z(\omega, T)$ determined by the s.d.e. $(2.19)$ as a timehomogeneous diffusion. ${ }^{6}$ Let $\tau_{1}=\tau_{1}(\omega)$ be the first arrival time of $z(\omega, \mathrm{t})$ at the level $z_{\triangleleft}$, then let $T_{1}=T_{1}(\omega)$ be the first arrival time at $z_{\triangleleft}+\delta$ after $\tau_{1}$, then $\tau_{2}$ the first arrival time at $z_{\triangleleft}$ after $T_{1}$ etc., the value $\infty$ being assigned if an arrival never occurs. These times are $\left(\mathscr{t}_{\mathrm{t}}\right)$-stopping times. For given $\omega$, the set $\left\{\mathrm{t}: z(\omega, \mathrm{t})<\mathrm{z}_{\triangleleft}\right\}$ is contained in the union of the intervals $\left(\tau_{\mathrm{i}}(\omega), \mathrm{T}_{\mathrm{i}}(\omega)\right)$, and for given $\mathrm{T}$ in the $\mathrm{i}^{\prime}$ th interval we have $z(T)=z_{\triangleleft}+x(T)-x\left(\tau_{i}\right)+\int_{\tau_{i}}^{T}\left[A\left(z_{t}\right)-O(t)\right] d t>z_{\triangleleft}+x(T)-x\left(\tau_{i}\right)+\left[\psi_{0}^{\prime}-N-\delta\right]\left(T-\tau_{i}\right)$

6 Terminology varies, but in any case the process $z(t)$ satisfies both the definition of a 'time--homogeneous Markov diffusion' given by Gihman and Skorokhod [1972], see esp. Ss.9-10 and 15, and the definition of a 'process of diffusion type' given by Liptser and Shiryaev [1977]. We use properties of such processes given by these authors without recalling all the details. 
By virtue of these remarks, we have

$$
\begin{gathered}
E \int I_{-} e^{(1-b) z(t)+v(t)} d t \leq E \sum_{i=1}^{\infty}\left[\int_{\tau_{i}}^{T_{i}} e^{(1-b) z(t)+v(t)} d t\right] \\
\leq \exp \left\{(1-b) z_{d}\right\} \cdot E \sum_{i=1}^{\infty}\left[e^{v\left(\tau_{i}\right)} \int_{\tau_{i}}^{T_{i}}\left[e^{(1-b)\left[x(t)-x\left(\tau_{i}\right)+\left(\psi_{0}^{\prime}-N-\delta\right)\left(t-\tau_{i}\right)\right]+v(t)-v\left(\tau_{i}\right)}\right] d t\right] .
\end{gathered}
$$

Dropping the constant, replacing $(1-b) x+v$ by $w$ and the upper limit of integration

$T_{\mathfrak{i}}$ by $T=\infty$, it will be enough to prove the convergence of

$$
E \sum_{i=1}^{\infty}\left[e^{v\left(\tau_{i}\right)} \int_{\tau_{i}}^{\infty}\left[e^{w(t)-w\left(r_{i}\right)+(1-b)\left(\psi_{0}^{\prime}-N-\delta\right)\left(t-\tau_{i}\right)}\right] d t\right] .
$$

Since the $\tau_{i}$ are stopping times, it follows from the strong Markov property of Brownian motion that each variable $\mathbf{v}\left(\tau_{\mathfrak{i}}\right)$ is independent of the integral which follows it. Consequently (24) may be rewritten as a sum of products of expectations, and because of the strong Markov property and time homogeneity the integrals all have the same expectations, namely

$$
E \int_{0}^{\infty}\left[e^{w(t)+(1-b)\left(\psi_{0}^{\prime}-N-\delta\right) t}\right] d t=\int_{0}^{\infty}\left[e^{-b n t+(1-b)\left(\psi_{0}^{\prime}-N-\delta\right) t}\right] d t
$$

because $\mathrm{Ee}^{\mathrm{w}(\mathrm{t})}=\mathrm{e}^{-\mathrm{bnt}}$. Since $\mathrm{bN}=\mathrm{bn}+(\mathrm{b}-1) \psi_{0}^{\prime}$ by $(1.40)$, the coefficient of $\mathrm{t}$ in the last exponent is just $-\mathbf{N}+\delta(\mathrm{b}-1)$, which is negative by our choice of $\delta$, so that the integral converges. It therefore remains only to check the convergence of the series $\Sigma \mathrm{E} \mathrm{e}^{\mathrm{v}\left(\tau_{\mathrm{i}}\right)}$, or equivalently of the series $\mathrm{E} \Sigma \mathrm{e}^{\mathrm{v}\left(\tau_{\mathrm{i}}\right)}$. Write $\mathrm{v}\left(\tau_{\mathrm{i}}\right)=\mathrm{v}_{\mathrm{i}}$ for short. Note first that the variables $\tau_{i}-\tau_{i-1}$ for $i>1$ are independent of one another (and of $\tau_{1}$ ) and have identical distributions, so that by the strong Markov property the variables $v_{i}-v_{i-1}$ for $i>1$ are independent of one another (and of $v_{1}$ ) and have identical distributions. Thus

$$
\sum_{i=1}^{\infty} \mathrm{Ee}^{\mathrm{v}_{i}}=\mathrm{Ee}^{\mathrm{v}_{\mathrm{i}}} \cdot\left[1+\sum_{\mathrm{i}=2}^{\infty}\left[\mathrm{Ee}^{\mathrm{v}_{\mathrm{i}}-\mathrm{v}_{\mathrm{i}-1}} \cdot \mathrm{Ee}^{\mathrm{v}_{\mathrm{i}-1}-\mathrm{v}_{\mathrm{i}-2}} \cdot \ldots \cdot \mathrm{Ee}^{\mathrm{v}_{2}-\mathrm{v}_{1}}\right]\right] .
$$

Let $\mathrm{Ee}^{\mathrm{v}_{\mathrm{i}}-\mathrm{v}_{\mathrm{i}-1}}=\mathrm{D}$ for $\mathrm{i}>1$ and note that $\mathrm{Ee}^{\mathrm{v}_{\mathrm{i}}} \leq \mathrm{D}$. Now,

$$
\mathrm{e}^{\mathrm{v}(\mathrm{t})}=\mathrm{e}^{\mu_{\mathrm{v}} \mathrm{t}+\sigma_{\mathrm{v}} \mathrm{B}_{\mathrm{v}}(\mathrm{t})}=\mathrm{e}^{\sigma_{\mathrm{v}} \mathrm{B}_{\mathrm{v}}(\mathrm{t})-\frac{1}{2} \sigma_{\mathrm{v}}^{2}(\mathrm{t})} \cdot \mathrm{e}^{-\mathrm{q} t},
$$

and since $\exp \left\{\sigma_{v} \mathrm{~B}_{\mathrm{v}}(\mathrm{t})-\frac{1}{2} \sigma_{\mathrm{v}}^{2} \mathrm{t}\right\}$ is a continuous positive martingale and $q>0$ we have $\mathrm{Ee}^{\mathrm{v}(\tau)}<1$ for any stopping time $\tau$, hence also $\mathrm{D}<1$ taking into account the 
strong Markov property. Thus the right-hand side of (25) does not exceed $D\left(1+D+D^{2}+\ldots\right)$ and so is convergent. This completes the proof for $b>1$. The case $\mathrm{b}<1$ is similar except that the roles of small and large values of $\mathrm{z}$ are interchanged.\| 


\section{REF ERENCES}

Arrow, K.J., and Kurz, M. [1970], Public Investment, the Rate of Return and Optimal Fiscal Policy. Baltimore, Johns Hopkins Press.

Bourgtignon, F. [1974], "A particular Class of Continuous-Time Stochastic Growth Models", Journal of Economic Theory 9, 141-158.

Foldes, L.P. [1978], "Optimal Saving and Risk in Continuous Time", Review of Economic Studies 45, 39-45.

Foldes, L.P. [1996], "The Optimal Consumption Function in a Brownian Model of Accumulation - Part B: Existence of Solutions of Boundary Value Problems". In preparation.

Gihman, I.I. and Skorohod, A.V. [1972], Stochastic Differential Equations. SpringerVerlag.

Jacod, J. [1979], Calcul stochastique et problème de martingales. LN Math. No. 714, Springer-Verlag.

Koopmans, T.C. [1965] "On the concept of optimal economic growth", Pontificiae Academiae Scientarum Scripta Varia, also in Study week on the econometric approach to development planning, pp. 225-287. Amsterdam: North-Holland.

Liptser, R.S. and Shiryaev, A.N. [1977], Statistics of Random Processes I. SpringerVerlag.

Malliaris, A.G. and Brock, W.A. [1982], Stochastic Models in Economics and Finance. Amsterdam: North-Holland.

Merton, R.C. [1975], "An Asymptotic Theory of Growth under Uncertainty", Review of Economic Studies 42, 375-394.

Mirrlees, J, [1967], "Optimum growth when technology is changing", Review of Economic Studies 34, 95-124. 